Société d'histoire de la révolution de 1848 et des

révolutions du XIXe siècle

$41 \mid 2010$

L'Algérie au XIXe siècle

Alice PRIMI, Femmes de progrès. Françaises et Allemandes engagées dans leur siècle, 1848-1870,préface de Michèle Riot-Sarcey, Rennes, Presses universitaires de Rennes, 2010, 317 p. ISBN : 978-2-7535-1044-9. 20 euros.

Caroline Fayolle

\title{
OpenEdition
}

Journals

Édition électronique

URL : http://journals.openedition.org/rh19/4079

DOI : $10.4000 /$ rh 19.4079

ISSN : $1777-5329$

Éditeur

La Société de 1848

Édition imprimée

Date de publication : 15 décembre 2010

Pagination : 166-167

ISSN : 1265-1354

Référence électronique

Caroline Fayolle, «Alice PRIMI, Femmes de progrès. Françaises et Allemandes engagées dans leur siècle, 1848-1870,préface de Michèle Riot-Sarcey, Rennes, Presses universitaires de Rennes, 2010, 317 p. ISBN : 978-2-7535-1044-9. 20 euros. », Revue d'histoire du XIXe siècle [En ligne], 41 | 2010, mis en ligne le 29 décembre 2010, consulté le 25 mars 2021. URL : http://journals.openedition.org/rh19/4079 ; DOI : https://doi.org/10.4000/rh19.4079

Ce document a été généré automatiquement le 24 mars 2021

Tous droits réservés 


\section{Alice PRIMI, Femmes de progrès. Françaises et Allemandes engagées dans leur siècle, 1848-1870,préface de Michèle Riot-Sarcey, Rennes, Presses universitaires de Rennes, 2010, 317 p. ISBN : 978-2-7535-1044-9. 20 euros.}

\section{Caroline Fayolle}

1 L'ouvrage d'Alice Primi restitue le parcours de femmes engagées en France et en Allemagne, de la Révolution de 1848 à la guerre de 1870. S'affirmant «filles de leur siècle ", ces femmes ont cherché à s'intégrer dans la marche du Progrès pour justifier leurs revendications d'accéder à la Cité. Pour étudier leurs luttes et leurs stratégies, l'historienne articule la méthodologie du genre et celle du comparatisme, en analysant à la fois l'impact des contextes nationaux sur la construction des catégories sexuées, et la fonction politique du genre dans la fabrique des identités nationales. L'important corpus de sources est constitué notamment par des périodiques français et allemands, et par des ouvrages écrits par les femmes étudiées (brochures et essais politiques, romans, correspondances, etc).

La première partie s'intéresse à l'engagement, lors de la Révolution de 1848, de femmes comme Louise Otto en Allemagne, ou Jeanne Deroin en France. L'auteure met en lumière les mécanismes d'exclusion politique des femmes, qui découlent de la construction de la figure du citoyen sur le modèle masculin, mais aussi les résistances de certaines militantes. L'approche comparative lui permet de dégager des différences entre l'action des révolutionnaires françaises et celle des Allemandes. Alors que les premières sont influencées par les courants utopistes des années 1830-1840, les 
secondes s'inscrivent dans le sillon des mouvements de la dissidence religieuse ou ceux de l'unification nationale. Si les militantes françaises insistent sur la nécessité de concrétiser pour toutes et tous les idéaux républicains, les Allemandes sont plus modérées dans la mesure où le contexte de la construction nationale les oblige, pour être entendues, à incarner les «vertus germaniques » et à s'opposer aux conceptions universalistes françaises.

3 La seconde partie se concentre sur les années 1850-1860 qui, loin de se résumer à un temps de repli après 1848 , sont l'occasion pour des femmes de mener des expériences spécifiques. L'écriture engagée, particulièrement dans la presse, est perçue par des femmes de cette période comme la clé donnant accès à la Cité. Alice Primi a recensé seize femmes (parmi lesquelles on trouve Jenny d'Héricourt en France, Fanny Lewald en Allemagne) qui ont manié la plume pour s'engager dans des journaux des années 1850-1860. Étudiant de manière lumineuse leurs parcours, l'auteure souligne les contraintes de genre, intériorisées ou non, qui pèsent sur ces journalistes.

4 La troisième partie de l'ouvrage examine le retour des femmes à l'engagement collectif à partir du milieu des années 1860. En Allemagne, le tournant se situe en 1865 avec le retour de Louise Otto à l'engagement associatif, notamment au sein de l'Association générale des femmes (Allgemeiner Deutscher Frauenverein / ADF). La rupture en France s'observe quant à elle en 1868 , alors que l'instauration des réunions publiques permet à des femmes de prendre la parole, et les encourage à prolonger leur engagement dans l'Association pour la revendication des droits des femmes, dont la principale instigatrice est André Léo. La fin des années 1860 voit aussi la parution du journal français Droits des femmes, dont le rédacteur en chef est Léon Richer, et de Neue Bahnen, l'organe de presse de l'ADF. Ce dernier, pourtant moins transgressif des normes de la « féminité » que le journal français, est le seul qui ose aborder la question des droits politiques. Les revendications des Allemandes à une "égalité dans la différence", atténuant le caractère subversif de leurs propos, leur permettent de s'aventurer dans le domaine de la politique. Sur la question du rapport entretenu par ces journaux avec les mouvements ouvriers, il apparaît que les rédactrices, souvent issues de milieux aisés, renoncent au projet initié par des militantes de 1848 d'allier la lutte pour les droits des femmes à celle des prolétaires. Les femmes engagées furent aussi contraintes d'abandonner leurs positions pacifistes pour reprendre les discours bellicistes et nationalistes imposés par la guerre de 1870. Malgré leurs efforts visant à adapter leurs revendications aux enjeux politiques généraux, ces femmes apparaissent « irrémédiablement en décalage, à l'écart, à contresens de l'Histoire qui s'impose, et du Progrès tel qu'il est défini par les dominants » (p. 278). La mise à l'écart de ces femmes révèle que la hiérarchie entre les sexes est un des socles de l'ordre social.

Interrogeant depuis des points de vue marginalisés les fondements politiques des sociétés française et allemande, cet ouvrage illustre magistralement l'intérêt heuristique du concept du genre pour éclairer l'histoire politique du XIX ${ }^{e}$ siècle. 